\title{
Transparency in research and publications on COVID-19
}

Reaching the third week of October/2020, a mark of more than 40 million confirmed cases associated with the frightening number of 1,119,431 deaths, ${ }^{1}$ the emergency of COVID-19 marked changes in the world's populationliving habits. From basic preventive measures, such as social distancing, frequent hand hygiene using soap and water or $70 \%$ alcohol, and the use of face masks, to rigorous obligatory preventive measures, such as a total closure of a certain area, known as lockdown.2,3 Although these initiatives are directed to the population's well-being, it has caused profound economic, social repercussions (leisure, religious and work), access to school and environmental education, which has caused psychological suffering to the majority of the population, regardless of age, schooling or socioeconomic level.4,5

With the announcement of the pandemic, an infectious agent unknown to the World Health Organization (WHO), besides the potential severity of COVID-19, there was an urgent need to develop research and data dissemination in record time, through free and easy access on new information to be given to the entire population and health managers, in conducting public practices and policies with maximum coherence and ethics. Consequently, there was an explosion in the number of publications in a short space of time. Just as an example, in a little more than nine months after the first publication on SARS-CoV-2, there are already 3,541 researches registered in Clinical Trails and more than 100,000 articles have been published, according to a search carried out in COVID-19 global literature on coronavirus disease, a database developed by WHO. 6

If on the one hand this initiative permitted a rapid dissemination of knowledge, unfortunately it had some negative effects. The desire for this dissemination has given rise to several publications of study data with less methodological rigor, such as case reports, since COVID-19 is no longer considered rare or unusual. Likewise, surveys with restricted sample size, expert opinion articles and even some frauds also populated the scientific scenario. This urgent need for new information and the constant updating of evidence discovered through national and international guidelines has generated much anxiety in the academic fields and the general population, with controversies about the effectiveness of some drugs for treatment or prevention, the prognosis of the disease, basic interventions and preventive measures and the development of vaccines.

Much of this research was published in pre-print format, even before being reviewed by ad hoc referees, a fact that should be carefully analyzed, especially when it comes to scientific publications. This problem was highlighted when a published article needed to be removed by the editors, after concluding, through an audit, that it was about fraud. ${ }^{7}$ Thus, it concluded that, despite the need for this publication process to be agile, it is undoubtedly essential to consider the methodological rigor in the execution and description of the results and transparency in all phases of the process, so that scientific publications are important tools in the decisionmaking of public health managers at a global level.

The Instituto de Medicina Integral Prof. Fernando Figueira (IMIP), since 1960, is a health care institution that works in assistance, teaching, research and extension, and during this pandemic, it has become a reference unit in the care of patients with COVID-19 in all age groups and population. Besides assisting patients affected by the disease, IMIP supports the performance of several institutional researches or in partnership with other 
national and international institutions. Thus, it also recognized the need to participate in the dissemination of knowledge, facilitating the publication of Brazilian surveys, particularly in the Northeast region of Brazil.

Thus, and in partnership with the Brazilian Journal of Mother and Child Health (RBSMI), IMIP supported a special issue on COVID-19, with the collaboration and commitment of the editorial board. This is a more diversified issue, extrapolating the usual maternal and child health scope of the journal, accepting articles from several areas.

We emphasize the importance of the suitability of the journal, which has not prioritized the articles from the institution. All opinions were carried out by trained researchers, where a conflict of interest statement was issued, justifying that although they are employees from IMIP, all the evaluations were issued by ad hoc referees. The need in calling in these reviewers was extremely important, as we had a number of articles submitted above the expected, and we needed agility in the opinions for theacceptance or rejection of the articles.

We received research of various modalities, points of view, original articles, case reports, systematic or narrative reviews, special articles and technical reports, which were selected following all the usual editorial processes of the journal, including a minimum of two referees per article to be evaluated. We emphasize that the refusal of articles in this issue has remained at more than $80 \%$ at the same level as the regular articles received.

We would like to thank everyone who submitted their articles and also all the editorial team and reviewers, indispensable actors for this project.

To those authors who submitted articles and who were not contemplated for this special issue of RBSMI, we hope that the fact does not discourage you and we always count on your valuable collaboration for submitting manuscripts on your new research.

\section{References}

1. World Health Organization (WHO). WHO Coronavirus Disease (COVID-19) Dashboard. Published 2020. [accessed October 21, 2020]. https://covid19.who.int/

2. Fisher D, Heymann D. Q\&A: the novel coronavirus outbreak causing COVID-19. BMC Med. 2020; 18(57): 1-3 DOI: https://doi.org/10.1186/s12916-020-01533-w.

3. World Health Organization. Considerations in adjusting public health and social measures in the context of COVID-19: interim guidance, 16 April 2020. World Health Organization. Published 2020. [accessed October 21, 2020]. https://apps.who.int/iris/handle/10665/331773.

4. Droit-Volet S, Gil S, Martinelli N, Andant N, Clinchamps M, Parreira L, Rouffiac K, Dambrun M, Huguet P, Dubuis B, Pereira B. Time and Covid-19 stress in the lockdown situation: Time free, «Dying» of boredom and sadness. PloSone. $2020 ; 15$ (8): 0236465.

5. Almeida MO, Portugal TM, Assis TJCF. Gestantes e COVID-19: isolamento como fator de impacto físico e psíquico. Rev Bras Saúde Mater Infant. 2020; 20 (2): 599-602.

6. World Health Organization (WHO). Global research on coronavirus disease (COVID-19). Published 2020. [accessed October 21, 2020]. https://www.who.int/emergencies/diseases/novel-coronavirus-2019/global-research-on-novel-coronavirus-2019-ncov.

7. Mehra MR, Desai SS, Ruschitzka F, Patel NA. RETRACTED: Hydroxychloroquine or chloroquine with or without a macrolide for treatment of COVID-19: a multinational registry analysis. Lancet. 2020; 395 (10240): 1820. 
Alex Sandro Rolland Souza 1

iD http://orcid.org/0000-0001-7039-2052

Afra Suassuna Fernandes 2

iD https://orcid.org/0000-0003-4027-3719

Lygia Carmem de Moraes Vanderlei 3

(iD https://orcid.org/0000-0002-3610-3699

Aurélio Antônio Ribeiro da Costa 4

(iD) http://orcid.org/0000-0003-4979-3905

Ana Laura Carneiro Gomes Ferreira 5

iD http://orcid.org/0000-0001-9172-6162

Luciana Santos Dubeux 6

iD https://orcid.org/0000-0002-7142-5191

Cynthia Braga 7

iD https://orcid.org/0000-0002-7862-6455

José Eulálio Cabral Filho 8

iD https://orcid.org/0000-0001-9121-9910

1-8 Instituto de Medicina Integral Prof. Fernando Figueira. Rua dos Coelhos, 300. Boa Vista. Recife, PE, Brasil. 